\section{Discourse Style and Situation Viewpoint for a Conversational Language Tutor}

\author{
Raza Hashim and Henry Hamburger \\ Department of Computer Science \\ George Mason University \\ Fairfax, Va 22030 \\ email:rhashim@gmuvax2.gmu.edu \\ henryh@aic.gmu.edu
}

Perspective, Rationale and Organization

hat should a conversational foreign language tutoring system say next? The choice is nstrainud by two sets of considerations: the demands of conversational continuity and the Ifualge progress of the student. An introduction to these potentially conllicting fuirements is the topic of an earlier paper [1]. The present study provides a more inical analysis of the conversational side of the problem by developing a framework with "key conversational structures: interaction mode and conversational viewpoint. In the urse of the investigation, it also becomes necessary to examine issues of knowledge pusintation and implententation for a two-way, two-medium communication system, one .1 Lats tutor and student converse spatially and linguistically.

' the outset, the reader may well wonder just what a conversational language tutoring siteil mught look like and why one should expect it to be useful. One may also seek some 16 to how it is organized, to gain perspective on the role played by discourse and cwpoint, the main subject maller of this paper. We take up these preliminary questions atly, in turn.

ce purpose of a conversational - or immersive - language learning environment is to help student to understind and use a new foreign language directly and automatically, as opposed to carrying out conscious mental translation or computation of brammatical formulas. To this end, we get the computer to provide some of the inmursion activities that successful language tutors often use, involving familiar physical objects used to act out familiar scenarios. Following these methods, we make use of the student"s own (lirst) language only to set the slage, and leave the explicit leaching of gramuar to others. Immersion nust be gradual, with exposure and comprehension of language preceding its production. Gradualness also means introducing new words and palterns onc at a time, in situations where they can be figured out from the rest of the sentence in the context of the visual activity and the continuily of the subject matter in the conversation. It is this ned for conversational continuity that motivales the work below.

To lix ideas, it may help to have a concrete example of the kind of objects and scinaros that are involved here. In one microworld that we call Washroom World, there is a figure whose movable hand enables him to tum on the water and to pick up, use and put down varuous objects like the soap, towel or toothbrush as needed. Such actions can combut to form composite actions that result in gelling his lace or teeth cluan, and so on. The hand can he controlled by either student or system, and the sequence of events is quite llexihle. Forcign language descriptions, comments, commands and questions are lightly interwoven with the screen events.

Space does not permil proper treatment of the second and third preliminary fint:stoms, llumed of motivation and organization. On motivation, see our earlier work 12 / and the himaler discussion by [3]. The approach is best suiled for the early stages and can be used with other systems - as well as teachers and books - that complement it.

As for organization, viewing matters very coarsely, one may say that the system hits three broad functions: to handle input, make internal updates and decisions, and generate uutput. Breaking these down in turn, input involves handling what the student says and does. This means robust natural language understanding with error analysis as well as interpretation of graphics (mouse) actions, each interpreted in their mutual conlext. As for output, it tow it bimodal and involves corresponding challenges. Internally, the system is expmothe tom 
naintaining models of the situation, the discourse, and the student, and for making tutorial ceisions about what to saly and do. The preceding few sentences suggest ten modules, five ach for the internal dutiss and for input/output. Each of the ten ofters ample opportunity for complex reasoning. To make such an ambitious undertaking managuable we are making ome judicious compromises and procededing in stages. A pilot system has been built that provides sone useful immersion experiences. A more modular, tlexible and elaborate system is under construction.

\section{The Structure of What to Say}

The system and the student need to maintain a coherent dialog so that both parties have a pliysscal and linguistie comlext in which to interprel and fommlate new sentences. A concrete physical situation is important, since the dialog is in the new language, which the viludent doesn't understand completely. The partially animaled graphical interaction on the computer sclecen indicules the physical context in which both the system and the student formulate and interpret utterances. The linguistic context, on the other hand, gradually develops as both parties succeed in communicating their intent to each other. This reyultument of maintaining a shared context is present for conversation in general [4] but is mort important for language tutors since they need a language-independent source of intormation aboul what is being said, to support the learning of new language aspects without Iranslation.

Section 2.1 introduces our approach to the problem of conversational continuity and states sume primciples for achicving clarity in the conversation. The next section deals with microworlds, discussing what aspects need to be represented, including goals and actions. In section 2.3, we present dialog schemas and interaction lypes that have been developed to maintain conversattional continuity. The linal subsection indicates how language diversity can be achicved by allernative views of an event and its results.

\subsection{Approach und Principles}

To actiteve conversational continuity the FLUENT system netds to (1) structure th student-tutor discourse, and (2) decide which aspect of the current situation to talk atum! We structure the student-lutor discourse by maintaining a three-level discout representation. At the top level is the dialog schema, a skeletal plan of the studint-tut,. interaction. A dialog schema is composed a flexible sequence of interchanges between it. student and the tutor. Each interchange, in turn, comprises of a small number of titin. possibly as few as one, by each party. Each turn is a linguistic and/or spatial output bu either the student or the tutor. The second issue, what particular asject or viese of it situation to talk about, is the responsibility of the view selector, which must be sensulue ben! to student needs and to the discourse structure just sketched. In the process of consiructim, the student-tutor dialog wo adhere to the following principles that help maintan clatily.

For educational continuity:

1. Present input to the student in order of incretsing linguistic complt:xity.

2. Present only one new linguistic aspect in a sentence and only a few til a lessenn.

3. Assume compreliension of an atspect before denanding its production.

For conversational continuity:

4. Keep students aware of the discourse structure.

5. Make comments that art relevant to the current situation.

6. In a new situation, make view selection relatively repelitive.

To control the ambiguity of the visual channel:

7. Kesp the number of objects low.

8. Talk about physical objects and their visible properties before talking about alswrat of invisible properties.

9. Also defer talk of abstract actions and goals. 
- Representing the Domain: Goals and Actions

Ihs section we dexcribe how to represent goals and actions in the microworld. Examples cribed in this suction will be used in sections 2.3 and 2.4 to show how to talk about these Is and actions. The state information of the objects in the microworld has been icsinted as a simple object syslem with inheritance. Since our ust of this approach to ics is familiar and straightforward, we focus on goals and actions.

I microworld, like the Washroou World mentioned above, we can talk about the goal that keng currently pursued, such as washing the fice, the action that is being carried out, $h$ as priking up an objet from the cabinet, or the state of a particular object, such as the - being dinty. In order to communicate effectively at these three levels, we maintain three Is of Jomain representation. At the top level is a model of the goals that can be pursued he microworld. In the Washroon World example mentioned earlier, these goals include hung one's lace, combing hair, brushing teeth, elc. With each goal there is a goal witure that tells the system how to achitve that goal, using primitive actions and/or other b)goals.

athm rules firm the second level of representation in the system. There are rules for whs such as picking up and putting down objects, as well as manipulating the states of Whes such as the faucets and the light switch. At the third level is a frame-based fescutition of the underlying microworld, which keeps track of the visible properties of sbjects in the microworld, like the cup being on the shelf, as well as invisible properties, the surfice state of the hand being wet.

pecific example of a goal structure is in Figure 1, which consists entirely of executable lug code. The goal in this example is to get a movable object - say a cup or a plate py, using a sponge. The object to be soaped must meet the conditions in the "pre" list, in indicites the the object is to be held in the stationary hand and should be dirty. The $1)^{\prime}$ indicales how soaping is actually carried oul, as a sequence of familiar actions. The wworld has a cabint, a sink, a sponge, and a bucket of soapy water. The character has a stalionary hand, which can hold one item at a lime, and a mobile hand, which can pick up one item at at time.

"Two points are worth mentioning about this goal structure. First, it does not recognize an arbitrary secpuence of actions as achieving a goal. A system construcled in this way will only recognize its predefined goal structures. In order to recognize arbitrary sequeates as goals we would need a deeper model of the Jomain. Sccond, it is possible to define the boal, siay soap $(X)$, as that of getting the surface-condition slot of the object $X$ as soapy using the predefined action rules of the system. We have chosen not to do this since planring a sequence of aclions in the microworld to achieve a particular goal can be a nontrivial task. For details on microworld planming see [S].

The second level of representation correspond to actions that can be observed grapheally These actions include thingss such as pick-up, put-down, brush-teeth, soap-by-sponge, etc Figure 2, which also is executable Prolog code, shows a typical action in the systelli. Sinte the characler in the microworld has only one mobile hand, we have chosen lo represent it by the constant, "m_hand". The rule transters an object to the mobile hand fionn the thung" that previously contained it.

The preconditions show that for this rule to be used, the mobile hand must be empty, the object to be transferred nust be movable, and it must be localed at the "From" ohjeet. In case the preconditions alre met, the system can execule the sule. To do so, it ivides the corresponding "act" and "mouse" conmands to the graphics component to carry out the action graphically, and updates the kuowledge base by carrying out all the items in the "post" or postconditions section of the rule.

The system ean aliso use this rule in reverse to detect a pick-up action that is carricd out by the student gaphically. In order lo do this it makes sure that the student's graphics actums matched the "mouse" and "act" component of this rule, and that all the preconditums ante met. If this is the case, the system can update the knowledge bast accondmgly hy areflung the postconditions. 


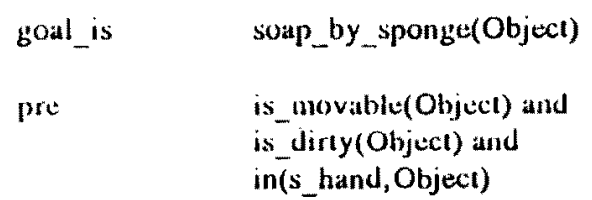

action:pick_up(sponge, cabinet) and action:soap_sponge(sponge, soap_water_bucket) and action:soap_by_sponge(Object) and action:put_down(sponge,cabinet) and action:put_down(Object,sink)

\section{Query $=. . \mid$ Object, surfuce, $=$, |soapy || and} call(Query).

Figure 1: Goal Structure for Soaping a Movabte Object.

1. The code given in this tigure is executable Prolog code. Variable names begin with upper casc letters while constauts are lower case.

2. "goal_is", "pre". "sub" and "post" are user defined operators.

Choosing the level of detail is an important issue in the design of a microworld. The primitive graphic actions in our microworld are visit and mouse actions. It is possible to Jescribe all actions in the system as a combination of these primitives. This, however, would mean reasoning from tirst principles about the state of the world, complicating the lasks of both microworld reasoning and language processing. We therefore model all actions will rules like the one in ligure 2, expressing a higher level action in terms of graphic primitives and microworld states. Such rules represent complex actions that are upplicable in rather special circumstances. Beside the one shown, other complex, specific rules deal with actions like wettmg movable objects, soaping objects by hand when the surface of the hand is soapy, and so on. For interpreting student actions, these rules are preferred over lle broadly applicable primitives. Modeling actions at this level simplifies language processing as well as reasoning, since languages typically have verbs at this level of aldiation.
rule
pick_object
do
gral(pick_up(Objecl,From))
mouse
nouse(mouseDown)
act
visit(m_hand, Object)
pre
value (m_hand, contains, $=$, empty) and
value(Object, is prop, =, Props) and
member(is_movable, Props) and
value(From,contains, $=$, Object)
post
Fact $=\ldots$ |From,contains, $=$, Object $\mid$ and
retract $($ Fact $)$ and
assert(hand(contains, $=$, Objuct))

Figure 2: Rule to Pick-up an Object.

1. The code given in this ligure is executable Prolog code. Variable nathes legint with ify case letlers while constants are lower case.

2. "rule". "do", "mouse", "act", "pre" and "post" are user defined operators wi appropriale precedence levels.

\subsection{Dialog Schemas and Interaction Modes}

In the previous section we looked at the knowledge representalten aceded to cittry in various goals and actions in an immersion style microworld. This scetion coven the that. schenas, interaction types, and views which are discourse tools neded to talk about gitit actions and states. We begin with dialog schemas, which guide comanumicalton will 11 , student, and more spextifically with the example in figure 3.

At the heart of the dialog schema in figure 3 are two types of interactums. In 11

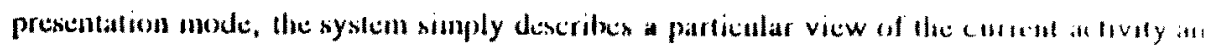

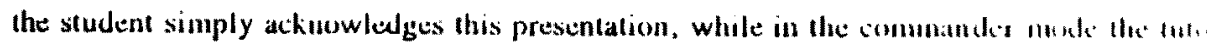
issues a command and the student carries it out graphically. In oudier to sumplat it 
cisentation of this example, it is assumed that the student will perforn each graphic action Mecessfully without errors in the commander mode. In the actual situation this might not the case. We can use discourse nanagentent strategies to make local plan repairs in case I incortect student responses and ensure that the student remains on track, for details see l.

presintation(goal:Goal, agent: Agent,

view:[describe_goul_to_do])

presentution(object:Object,slot:Slot, value: Value, view:[describe_state_value])

commander(goal:Goal,

view:(describe_action]).

presentation(object:Object,slot:Slot, value: Value, view: (describe state value now))

presentation(object:Object, slot:Slot, value:OldValue, view:[describe_state_value_before]).

pristuntation(goal:Goal,

view:[describe_goa!_action]).

Figure 3: A dialog schema that uses Presentation and Commander mode

Hppose we instantiatt this schema with the goal soap-by-sponge, with the object "glass" and Int "surlice", and agent as the student. This can result in the bimodal dialog of figure 4. : he sentences in the ligure are to be produced by a natural language generation generator peratung on the output representation produced by our system. We are collaborating with he Alhena Language Learning Project [7] whose generator is capable of this kind of output.

Tlew specilic comments may help with understanding figure 4. Items (3-7) correspond to in: commander mode interaction while the other utterances correspond to the presentation inde. Wo will look at the commander mode interactions (3-7) first. In these pairs the utorial command is followed by the student performing the appropriate graphic actions in sponse. The expression "visit $(X, Y)$ " is generated when a reclangular frame for object $X$

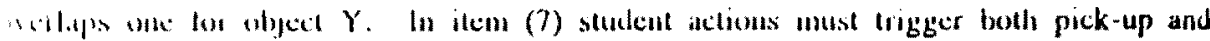

pul-down to take the glass from the stationary hand and pot it in the sink. As a result ot each lutorial command and student response, several updates occur in the moroworld, and several tutorial comments becone possible, by using different views, as explained in section 2.4
Tutor

1. You will soap the glass.

2. Il is dirty now.

3. Pick up the sponge.

4. Soap it in water.

5. Take the sponge to the glass.

6. Put it back in the cabinet.

7. Put the glass down in the sink.

8. Now the glass is suapy

9. Il was dirty, before.

10. You soaped it with a sponge.
Student

<acknowledge>

<acknowledge>

visit(m_hand, sponge)

mouse(mouse Down)

visit(sponge, soap water)

visil(sponge, glass)

visit(sponge, cabinet), mouse(mouse Down)

visit(m_hand, glass), mouse(mousedown)

visil(glass, sink), mouse(mouseDuwn)

<acknowled ge $>$

<acknowledge>

$<$ acknowledge >
Figure 4: A sample dialog based on the schema

If we add nore interaction lypes more interesting discourse schemas can be created. Somle of these occur in the current pilot system but are not implenented with the kind of llexihlily and generality we ultimately seck. Quizmaster is defined as a $(y p)$ of interachon that allows the tutor (o) ask students questions which they can respoun to graphically or lingukfually The Oracle interaction would let the student ask questions. either piching from a menu of options, or by typing in questions, and the systen responds. In the Movecaster mode, which is currently implemented with some generality, the system comnents on the graphic ation done by the student. Celebrity would be the reverse of Movecaster, allowing the sluteit to talk about system moves; the system would check for appropriateness. In the Servant noul. the student issues the commands and the tuter carries then out, agan with the possthblity of commenting on the goat, action and states that are relevant. Sume of these interactem types and some views are less demanding of student progress than whers, and the system thespones

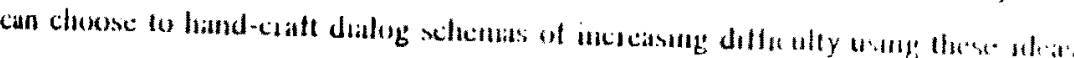


.4 Vicws

There is a great diversity in what the tutor can say at various timcs. For one thing, the Jalog schema given in Figure 3 can be used with other goal structures, for example, Ituctures for washing or drying objects. In this section we will see that even at one s.ticular time there are many conversationally relevant utterances that can be produced by the language tutor. For example, alter the interaction in line (3) of Figure 4, any of the wlowing sentences is reasonuble:

The sponge is in the hasd.

You picked op the sponge trom the cabinet.

The sponge is no longer in the cabinet.

1. You are holding the sponge.

ath of these utterances corresponds to a different view of the resulting situation. Such Hllances can be getlerated by lise tutor with more advanced students. With beginaing iudents, a good tutorial strategy would be to stick to the basic command and very little allow up. In case the student docsn't carry out the anticipated action, it would seem useful of the system to generate an ullerance describing what the student actually did. Figure 5 ives a selection from among dozens of possible views involving goals, actions, time and lie state of objects. Conmenting on less obvious aspects of the situation can provide mportint language exposure to the student. However, sonte of these views might be Ifficult to understand for the beginner since they corsespond to the physical situation only a an indiret way.

I view structurc is cssentially a frame, implemented in the same Prolog style as the action ules and goals. One slot contains the interaction type and view information. Another slot perties what intormation about the current situation will need to be consulled, lypically the Ind of action and its current (actual) arguments. A third stot specilies how to put the Afumatuon from the lirst iwo logether to construct a semantic structure to send to the ..thial language gencrator. It should be noted that the dialog schema given in Figure 3 can be used with other goal structures, for exanple, structures for washing or Jrying objects. Moreover, looking at the list of views in Figure $S$ one can see that if they are incorposated into the dialog schema given in ligure 3 many more conversationally aclevint ufterances can be produced by the language tutor.

Goal-Oriented Views:

- starting subjoal

- subgoal transition within the same goal

- goal completion

- violation of goal-based expectations

Aclion-Orienlud Views:

- action that was carried out

- mon-fecurrence of anticipated action

- same operator with another argument, negated

Temporal View:

- this action follows its predecessor

State-Oriented Views:

- new state of the object that has been acted upon

- previous state of the object acted upon

- composite observation ("Now, there are two ...")

- preceding state no longer holds

Figure 5: Views possible in a goal-oriented ulicroworld

\section{Summary}

Discourse style and situational viewpoint are key elenents of an immersion-slyle lamguage tutor. In order to achieve conversational continuity, such a system neds fo maintain a nodel of goats, actions and states in the microworld along with touls to manage disenense. The discourse management tools include various dialog schemas composed of interaction types. These schemas guide the communication protocol between the Nedcont and the latos, Another tool is the type of view that one takes of what oceurs in the microworld. The

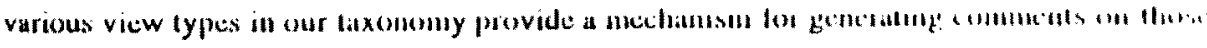

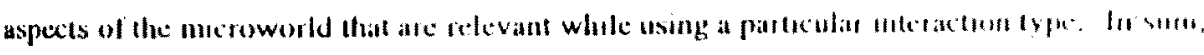


we have devised a variely of interaction types and views and shown how to use them in the construction of a bimodal, bidirectional communication system for imnersive forcign language learning.

\section{References}

1. Hamburger, H. and Maney, T. (1991) Twofold Continuity in Inmersive Language Learning. J. Computer-Assisted Language Learning 4,2: 81-92.

2. Hamburger, H. and Hashim, R. (1992) Foreign langauge tutoring and learning system. In M. Swartz and M. Yazdani (Eds.), Intelligent Tutoring Systems for Foreign Lunguage Learning. New York: Springer-Verlag.

3. Richards, J.C. and Rodgers, T.S.(1986) Approaches and Methods in Linguage Teaching; $A$ Description and Analysis. Cambridge: Cambridge Language Tcaching Library.

4. Grosz, B. and Sidner, C. (1987) Altention, intentions, and structure of discourse, Computational Linguistics 12,3: 175-204.

5. Wilensky, R. (1983) Planning and Understanding: A Computational Approath lo Human Reasoning. Reading, MA: Addison Wesley.

6. Novick, D. (1988) Doctoral Dissertation, University of Oregon, Lugenc, Oregr(m.

7. Felshin, S. (1991) The Lingo Manual. The Athena Language Luarning Projuct. MIT. 